1 Peutz JL. A very remarkable case of familial polyposis of the mucous membrane of the intestinal tract and nasopharynx accompanied by peculiar pigmentations of the skin and mucous membrane. Ned Tijdschr Geneeskd 1921;10:134-46. 2 Jeghers $\mathrm{H}$, McKusick VA, Katz KH. Generalized intestinal polyposis and melanin spots of the oral mucosa, lips and digits: a syndrome of dic 1949;241:1031-6.

3 Amos CI, Bali D, Thiel TJ, et al. Fine mapping of a genetic locus for Peutz-Jeghers syndrome on chromosome $19 \mathrm{p}$. Cancer Res 1997;57:3653-6.

4 De Facq L, De Sutter J, De Man M, Van der Spek P, Lepoutre L. A case of Peutz-Jeghers syndrome with nasal polyposis, extreme iron deficiency anemia, and hamartomaadenoma transformation: management by combined surgical and endoscopic approach. Am $\mathcal{f}$ Gastronterol 1995;90:1330-2.

5 Foley TR, McGarrity TJ, Abt AB. Peutz-Jeghers syndrome: a clinicopathologic survey of the 'Harrisburg family' with a 49-year follow-up. Gastroenterology 1988;95:1535-40.
6 Utsunomiya J, Gocho H, Miyanaga T, et al. Peutz-Jeghers syndrome: its natural course and management. fohn Hopkins Med f 1975;136:71-82.

7 Takehara H, Okada A, Nishi M, Masamune K, Komi N. Intra-operative total enteroscopy for the management of Peutz-Jegher's syndrome. Acta Paediatr fap 1992;34:569-

72.

8 Spigelman AD, Thompson JPS, Phillips RKS. Towards decreasing the relaparotomy rate in the Peutz-Jeghers syndrome: the role of peroperative small bowel endoscopy. Brf Surg 1990;77:301-2.

9 Spigelman AD, Murday V, Phillips RKS. Cancer and the Peutz-Jeghers syndrome. Gut 1989;30:1588-90.

10 Hizawa $\mathrm{K}$, Iida $\mathrm{M}$, Matsumoto $\mathrm{T}$, et al. Cancer in Peutz-Jeghers syndrome. Cancer 1993;72:2777-81.

11 Spigelman AD, Arese P, Phillips RKS. Polyposis: the PeutzJeghers syndrome. Br f Surg 1995;82:1311-4.

\title{
Abnormal liver function tests following inadvertent inhalation of volatile hydrocarbons
}

\author{
J R Pyatt, I Gilmore, P A Mullins
}

\begin{abstract}
Summary
The use of aerosols containing volatile hydrocarbons in conditions of poor ventilation can result in accidental overexposure which can cause central nervous system effects and hepatic injury. We present a case in which inadvertent usage of an adhesive spray used to make greeting cards resulted in vague neurological symptoms and abnormal liver function tests both of which fully resolved on discontinuation.
\end{abstract}

Keywords: liver function tests; volatile hydrocarbons; inhalation; neurological symptoms.

Elevated transaminases may occur following ingestion and vapour inhalation of some hydrocarbons. We report a case in which inadvertent inhalation resulted in hepatic injury and review the evidence for a link between the hydrocarbons contained in the spray and the patient's abnormal liver function tests.

\section{Case report}

Liverpool Royal University Hospital, Prescot Street, Liverpool, L7 8XP, UK Department of Cardiology J R Pyatt

P A Mullins

Department of Gastroenterology, I Gilmore

Correspondence to Dr JR Pyatt, 7 Rigby Street, Hindley, Wigan WN2 4BL, UK

Accepted 30 June 1998
A 63-year-old man attended the Accident and Emergency Department complaining of a 2-month history of non-specific malaise and paraesthesia in his left upper limb. Two days prior to his attendance a general biochemical screen and full blood count were performed by a commercial laboratory through a friend. The results showed an elevated serum alkaline phosphatase of $162 \mathrm{IU} / 1$ (normal range 50136); a serum aspartate transaminase of 73 IU/1 (15-37); a serum alanine transaminase of $122 \mathrm{IU} / 1$ (30-65) and a serum gammaglutamyltransferase of $108 \mathrm{IU} / 1(5-85)$. The serum bilirubin, albumin and protein were all normal. The patient had been previously well and was not taking any medication. He was a non-smoker and drank 1-2 units of alcohol weekly. He had never previously drunk alcohol excessively. On examination he appeared well, was not jaundiced or pyrexial and had none of the stigmata of chronic liver disease. No hepatomegaly or splenomegaly were detected and the rest of the general examination was unremarkable. Various investigations were arranged and he was discharged from hospital and followed up 3 weeks later in the out-patient clinic. His serological markers for acute viral hepatitis were negative. His serum ceruloplasmin and ferritin level and thyroid function tests were normal. His auto-antibody screen was negative. His abdominal ultrasound revealed an echobright pattern suggestive of mild fatty change and an incidental $2 \mathrm{~cm}$ gall stone without biliary tract dilation. A plain cervical spine radiograph showed minor degenerative changes only.

A week later the patient's wife, who worked for Age Concern, attended a drug abuse lecture and recognised the potential cause of her husband's symptoms. He was a keen producer of home-made greeting cards and spent up to 3 hours at a time, two to three times per week, in a poorly ventilated garage using $3 \mathrm{M}$ (TM) Spraymount Adhesive. He had been using it regularly for approximately 2 years but because of both a Christmas 'rush' to produce extra cards for a charity and excessive cold weather, this use had increased and with virtually no ventilation. The patient then confessed to symptoms of drowsiness and nausea. After stopping it completely and changing to a paste form of adhesive he felt dramatically better with complete cessation of his symptoms. Repeat liver function tests taken 4 weeks after the first set had returned to normal. 


\section{Discussion}

3M (TM) Spraymount Adhesive is an aerosol container with flammable liquid under pressure. It contains the non-halogenated hydrocarbons propane/butane/isobutane propellant (30-35\%), petroleum distillates (25-35\%), pentane $(10-15 \%)$ and acetone $(1-5 \%)$. Users are warned not to inhale the vapours, to use in a well-ventilated area, to avoid eye and skin contact and not to ingest. Inhalation can cause central nervous system depression and irritation to the upper airways. The product information does not indicate abnormal liver function tests as a possible hazard.

Elevated transaminases can occur following ingestion or vapour inhalation of either halogenated or non-halogenated hydrocarbons. Carbon tetrachloride is the best example of an hepatotoxic halogenated hydrocarbon and even small quantities can cause fatal hepatic effects after inhalation, ingestion or dermal exposure. ${ }^{1} \mathrm{He}$ patic injury, including hepatosplenomegaly, has rarely occurred after the ingestion or inhalation of petroleum distillates, ${ }^{2-4}$ whilst pentane was found to be only mildly hepatotoxic in animal studies. ${ }^{5}$ There are no reports of either butane or propane having hepatotoxic effects. Toluene and xylene are non-halogenated hydrocarbons that may have caused hepatic damage through inhalation. Hepatorenal dysfunction developed in a 19-year-old after inhalation abuse of toluenecontaining cleaning fluid. However, there was also a prior history of ethanol misuse and glue sniffing. ${ }^{6}$ Two survivors of exposure to xylene vapours at $10000 \mathrm{ppm}$ developed transiently raised liver transaminases but concomitant

1 Torkelson TR. Halogenated aliphatic hydrocarbons. In Clayton GD, Clayton FE, eds. Patty's industrial hygiene and toxicology, 4th edn. New York: John Wiley and Sons, 1994.

2 Janssen S, van der Geest S, Meijer S, et al. Impairment of organ function after oral ingestion of refined petrol. Inten organ function after oral inge

Care Med 1988;14:238-40.
3 Shirkey HC. Treatment of petroleum distillate ingestion. 3 Shirkey HC. Treatment of petrol
Mod Treatment 1971; 8:580-92.

Mod Treatment 1971; 8:580-92.
4 Gosselin R, Hodge H, Smith R, et al. Clinical toxicology of 4 Gosselin R, Hodge H, Smith R, et al. Clinical toxicology of
commercial products, 4th edn. Baltimore: Williams and Wilkins, 1976.

\section{Learning points}

- abnormal liver function tests and neurological symptoms can both occur through inadvertent exposure to volatile hydrocarbons contained in household aerosol containers, especially if used in poorly ventilated surroundings

- it is important to take a detailed history of patient's everyday hobbies and their use of household products which could be potentially harmful

hypoxia and toluene exposure may have contributed to these effects.?

These studies often involve accounts which are historical, high exposures sufficient to produce anaesthesia, and the use of products containing many different volatile substances, all of which make establishing a casual relationship between exposure and hepatic damage difficult.

It would clearly be unethical to rechallenge this patient with the individual hydrocarbons contained in the spray but there is still a strong temporal relationship between symptoms and hepatic damage with use of the spray and resolution with cessation. Many environmental toxins are metabolised to active hepatotoxins and it is likely that there was also a genetic predisposition to increased liver damage in this patient. It is always important to check that patients with similar vague neurological symptoms and abnormal liver function tests are not being inadvertently exposed to petroleumbased volatile substances.

5 Wirtschafter ZT, Cronyn MW. Relative hepatotoxicity. Arch Environ Health 1964;9:1980-5.

6 O'Brien ET, Yeoman WB, Hobby JAE. Hepatorenal damage from toluene in a glue sniffer. $B M \ngtr$ 1971;2:29-30. 7 Morley R, Ecclestone DW, Douglas CP, Greville WEJ, Scot DJ, Anderson J. Xylene poisoning: a report on one fatal case and two cases of recovery after prolonged unconsciousness. BMF 1970;3:442-3. 